\title{
Relationship of strain-dependent susceptibility to experimentally induced acute pancreatitis with regulation of Prss1 and Spink3 expression
}

\author{
Jun Wang ${ }^{1}$, Masaki Ohmuraya ${ }^{1,2,3}$, Koichi Suyama ${ }^{1,3}$, Masahiko Hirota ${ }^{3}$, Nobuyuki Ozaki ${ }^{1,3}$, Hideo Baba ${ }^{3}$, \\ Naomi Nakagata ${ }^{4}$, Kimi Araki $^{1}$ and Ken-ichi Yamamura ${ }^{1}$
}

To analyze susceptibility to acute pancreatitis, five mouse strains including Japanese Fancy Mouse 1 (JF1), C57BL/6J, $\mathrm{BALB} / \mathrm{C}, \mathrm{CBA} / \mathrm{J}$, and $\mathrm{C} 3 \mathrm{H} / \mathrm{HeJ}$ were treated with either a cholecystokinin analog, cerulein, or a choline-deficient, ethioninesupplemented $(C D E)$ diet. The severity of acute pancreatitis induced by cerulein was highest in $\mathrm{C} 3 \mathrm{H} / \mathrm{HeJ}$ and $C B A / J$, moderate in $\mathrm{BALB} / \mathrm{C}$, and mildest in $\mathrm{C57BL} / 6 \mathrm{~J}$ and JF1. Basal protein expression levels of the serine protease inhibitor, Kazal type 3 (Spink3) were higher in JF1 and C57BL/6J mice than those of the other three strains under normal feeding conditions. After treatment with cerulein, expression level of Spink3 increased remarkably in JF1 and mildly in C57BL/6J, $\mathrm{BALB} / \mathrm{C}, \mathrm{CBA} / \mathrm{J}$, and $\mathrm{C} 3 \mathrm{H} / \mathrm{HeJ}$ strains. Increased proteinase, serine, 1 (Prss1) protein expression accompanied by increased trypsin activity with cerulein treatment was observed in susceptible strains such as $\mathrm{CBA} / \mathrm{J}$ and $\mathrm{C} 3 \mathrm{H} / \mathrm{HeJ}$. Similar results were obtained with a CDE diet. In the $3 \mathrm{~kb}$ Spink3 promoter region, 92 or 8 nucleotide changes were found in JF1 or C3H vs C57BL/6J, respectively, whereas in the Prss 1 promoter region 39 or 46 nucleotide changes were found in JF1 or C3H vs C57BL/6J, respectively. These results suggest that regulation of Prss1 and Spink3 expression is involved in the susceptibility to experimentally induced pancreatitis. The JF1 strain, which is derived from the Japanese wild mouse, will be useful to examine new mechanisms that may not be found in other laboratory mouse strains.

Laboratory Investigation (2010) 90, 654-664; doi:10.1038/labinvest.2010.44; published online 15 February 2010

KEYWORDS: serine protease inhibitor, Kazal type 3 (Spink3); proteinase, serine, 1 (Prss1); single-nucleotide polymorphisms (SNPs)

Over 450 inbred strains of mice have been described, ${ }^{1}$ providing a wealth of different genotypes and phenotypes for studying human diseases. Actually, the use of various breeding strategies in combination with positional cloning and positional candidate gene approach has led to the discovery of many genes that underlie human disease. ${ }^{2}$ The Japanese wild mouse, belonging to Mus musculus molossinus, has several genetic characteristics clearly distinguishable from the European wild mouse, derived from M.m. domesticus. These subspecies were separated about one million years ago and about $1 \%$ of their genome sequences are different. ${ }^{3-8}$ Therefore, strains MSM/Ms ${ }^{9}$ and Japanese Fancy Mouse 1 (JF1) ${ }^{10}$ which were established from M.m. molossinus, are powerful genetic resources to analyze disease processes.

Many inbred strains have been bred for specific phenotypes. C57BL/6J mice are susceptible to high-fat diet-induced type II diabetes. ${ }^{11}$ JF1 mice are especially sensitive to high-fat diet-induced diabetes and obesity, whereas MSM/Ms mice are resistant. ${ }^{12}$ To date, however, there is little information about the difference in severity of pancreatitis among inbred strains of mice.

Acute pancreatitis is an important disease that can be triggered by a variety of factors, including excessive alcohol consumption, ${ }^{13-16}$ obstruction of the ampulla of Vater by gall stones, ${ }^{17,18}$ and genetic factors. ${ }^{19,20}$ Hereditary chronic pancreatitis is a rare form of early onset chronic pancreatitis, characterized by the onset of recurrent attacks of acute pancreatitis in childhood, and frequently progresses to chronic pancreatitis. One type of the hereditary pancreatitis is caused by a mutation in the proteinase, serine, 1 (PRSS1) gene, encoding cationic trypsinogen. PRSS1 mutation results in an amino-acid substitution in the autolytic domain of

\footnotetext{
${ }^{1}$ Division of Developmental Genetics, Institute of Molecular Embryology and Genetics, Kumamoto University, Kumamoto, Japan; ${ }^{2}$ Priority Organization for Innovation and Excellence, Kumamoto University, Kumamoto, Japan; ${ }^{3}$ Department of Gastroenterological Surgery, Kumamoto University, Kumamoto, Japan and ${ }^{4}$ Center for Animal Resources and Development, Institute of Resource Development and Analysis, Kumamoto University, Kumamoto, Japan

Correspondence: Dr K-i Yamamura, MD, PhD, Institute of Molecular Embryology and Genetics, Kumamoto University, 2-2-1 Honjo, Kumamoto 860-0811, Japan.

E-mail: yamamura@gpo.kumamoto-u.ac.jp

Received 18 August 2009; revised 13 January 2010; accepted 13 January 2010
} 
trypsin. Thus, the mutation blocks autolysis and results in continuous trypsin activity. ${ }^{21,22}$ In addition, mutation of the trypsin-specific inhibitor, serine protease inhibitor, Kazal type 1 (SPINK1), has been found to be associated with chronic pancreatitis as well. ${ }^{23}$ We earlier showed that Spink3 (mouse homolog of human SPINK1) has dual functions for trypsin inhibition: one as a trypsin inhibitor by direct binding to trypsin ${ }^{24}$ and another as a suppressor of autophagy, which is involved in trypsinogen activation. ${ }^{25,26}$ In summary, mutations in PRSS1 ${ }^{27}$ and SPINK $1^{19}$ genes are acknowledged as genetic risk factors for pancreatitis in human patients.

To address whether genetic background can affect the development of acute pancreatitis in relation to expression of Prss1 and Spink3, the susceptibility of acute pancreatitis was compared among five inbred mouse strains including JF1 in two models of experimental acute pancreatitis, cerulein-induced and choline-deficient ethionine-supplemented (CDE) diet-induced acute pancreatitis. We found that there were significant differences in susceptibility to acute pancreatitis among mouse strains, and that susceptibility to acute pancreatitis was negatively or positively related with expression levels of Spink3 or Prss1, respectively. In addition, sequence differences in Spink3 promoter regions between JF1 and other strains were considered to be involved in differences in expression levels.

\section{MATERIALS AND METHODS Mouse Strains}

All procedures were approved by the Animal Care and Use Committee of Kumamoto University. The five mouse strains were used in the following experiments: JF1 (Riken BioResource Center, Tsukuba, Japan), C57BL/6J, CBA/J, and BALB/c (CLEA Japan, Inc. Tokyo, Japan), and C3H/HeJ (Charles River Laboratories Japan, Inc. Yokohama, Japan). For every experiment, five mice in each strain were assigned to either a control or experimental group.

\section{Cerulein-Induced Pancreatitis}

After an overnight fast, mice were given hourly intraperitoneal injections of either saline (control) or cerulein $(50 \mu \mathrm{g} / \mathrm{kg})$ (Sigma-Aldrich Corp, Tokyo, Japan) for $12 \mathrm{~h}$. One hour after the last injection, serum and the pancreas were isolated for the following studies.

\section{CDE Diet-Induced Pancreatitis}

Composition of CDE chow was described earlier. ${ }^{28}$ Mice were fasted for $24 \mathrm{~h}$ and then fed with either CDE or control (regular laboratory chow) diet for $72 \mathrm{~h}$. Then, animals were fed with regular laboratory chow for $12 \mathrm{~h}$ before they were killed.

\section{Histological Examination and Pathologic Scoring}

For histological analysis, pancreatic tissue was fixed overnight in $10 \%$ formalin, embedded in paraffin, sectioned, and stained with hematoxylin and eosin. The extent of injury was estimated using a method described earlier with some minor modifications. ${ }^{29}$ Briefly, 10 randomly chosen microscopic fields were examined for each pancreas specimen, and the total surface of the slide was scored for five different variables determining severity of inflammation: edema (E), hemorrhage $(\mathrm{H})$, inflammatory cell infiltration (I), acinar cell vacuolization $(\mathrm{V})$, and acinar cell necrosis $(\mathrm{N})$. Total scores for these five parameters were obtained in each group after mapping the pancreas into 10 fields and evaluating each field independently.

\section{Serum Amylase Activity}

Mouse blood was used to measure pancreatic amylase activity using substrate, 2-chloro-4-nitrophenyl-4-galactopyranosylmaltoside (Gal-G2-CNP) (CicaLiquid-N p-AMY, Kanto Chemical Co., Inc. Tokyo, Japan).

\section{Measurement of Trypsin Activity}

Measurement of trypsin activity was performed as described earlier. $^{25}$

\section{Northern Blot Analysis}

Total RNAs were extracted from the pancreas with Sepasol (Nacalai Tesque, Kyoto, Japan). For making digoxigeninlabeled RNA probes (Roche Molecular Biochemicals, Germany), mouse Spink3 and Prss1 probes were derived from mouse pancreas RNA by reverse transcriptase PCR using the following nucleotide sequences: mPstil (agttcttctggcttttgcaccc) and mPsti26 (cccacgttgcctttcattacgg); Prss1: mPrss1-s1 (taaaggcaggcttccatccagg) and mPrss1-a1 (tgacagtgactgcagagggatt). cDNA was subsequently subcloned into a pGEM-T easy vector (Promega, Madison, WI, USA).

\section{Sequence Analysis}

Both cDNAs and the promoter regions of Spink3 and Prss 1 gene were amplified by PCR using TaKaRa LA Taq polymerase mix (Takara Bio Inc., Kyoto, Japan). Primers used in the RT-PCR included the following sequences: mPstil (agttcttctggcttttgcaccc) and mPsti26 (cccacgttgcctttcattacgg) for Spink3; mPrss1-s1 (taaaggcaggcttccatccagg) and mPrss1a1 (tgacagtgactgcagagggatt) for Prss1. Three pairs of primers were applied to sequence the $3 \mathrm{~kb}$ promoter region of each gene. Sequencing was performed using the Big Dye Terminator Cycle Sequencing ready kit and an ABI 310 Genetic Analyzer (Applied Biosystems).

\section{Western Blot Analysis}

Western blot analysis was carried out according to the method described earlier. ${ }^{25}$ Primary antibodies to the following antigens were used at the indicated dilutions: Spink3 (Transgenic Inc., Kumamoto, Japan), 1:1000; Prss1 (Nordic immunological laboratories, Tilburg, Netherlands), 1:1000; amylase (Santa Cruz Biotechnology, CA, USA), 1:1000; and light chain 3 (LC3) (MBL International, Woburn, MA, USA), 
1:1000. An anti-rabbit secondary immunoglobulin G antibody conjugated with horseradish peroxidase (Amersham Biosciences Corp, Piscataway, NJ, USA) was used to detect all proteins. Intensities of the bands were quantified by densitometry using ImageJ software (version 1.38 , a program inspired by NIH image; http://rsb.info.nih.gov/ij/docs/ index.html).

\section{Statistical Analysis}

All values are presented as mean \pm s.d. (range, $95 \% \mathrm{CI}$ ), and statistical analysis was performed applying unpaired Student's $t$-tests. $P<0.05$ was considered to be a statistically significant difference.

\section{RESULTS}

\section{Cerulein-Induced Pancreatitis}

The pancreas of all strains of mice injected with normal saline showed no histological changes, whereas cerulein treatment induced variable degrees of acute pancreatitis among these five strains (Figure 1). C57BL/6J mice showed the mildest pancreatitis (Figure $1 \mathrm{~g}$ and $\mathrm{h}$ ), whereas $\mathrm{C} 3 \mathrm{H} / \mathrm{HeJ}$ mice displayed the most severe pancreatitis (Figure $1 \mathrm{~s}$ and $\mathrm{t}$ ). BALB/c and $\mathrm{CBA} / \mathrm{J}$ mice showed a moderate degree of pancreatitis (Figure $1 \mathrm{k}, \mathrm{l}, \mathrm{o}$ and $\mathrm{p}$ ). Acute pancreatitis in JF1 mice was obviously milder than pancreatitis in $\mathrm{BALB} / \mathrm{c}$ and $\mathrm{CBA} / \mathrm{J}$ mice, yet more severe than C57BL/6J with evidence of acinar cell necrosis (Figure 1c). Further calculations of semi-quantitative pathologic scores and statistical analysis strongly supported this statistical difference in susceptibility (Figure $1 \mathrm{u}$ and $\mathrm{v})$. Levels of amylase coincide with histological findings, highest in $\mathrm{C} 3 \mathrm{H} / \mathrm{HeJ}$, followed by $\mathrm{CBA} / \mathrm{J}$ and BALB/ c, and lowest in $\mathrm{C} 57 \mathrm{BL} / 6 \mathrm{~J}$ and JF1 with statistically significant differences $(P<0.05)$ (Figure $1 \mathrm{w})$. Interestingly, serum levels of amylase in JF1 mice were lowest in spite of the presence of low grade of acinar cell necrosis when compared with C57BL/6J mice.

\section{CDE Diet-Induced Pancreatitis}

In CDE diet-induced pancreatitis, the general histological appearance of pancreatic tissues was much milder than those in cerulein-induced pancreatitis. Acinar cells presented almost no obvious histological changes in JF1, C57BL/6J or $\mathrm{BALB} / \mathrm{c}$ mice (Figure 2c, d, g, h, k and $\mathrm{l}$ ). $\mathrm{C} 3 \mathrm{H} / \mathrm{HeJ}$ mice, however, showed signs of obvious necrosis in acinar cells together with infiltration of inflammatory cells and slight vacuolization of acinar cells (Figure $2 \mathrm{~s}$ and $\mathrm{t}$ ). A mild degree of acinar cell necrosis was observed in CBA/J mice (Figure 2o and $\mathrm{p}$ ). Peripancreatic hemorrhage was a frequent sign observed in this model as shown in Figure 2l, whereas fewer inflammatory cells were found within the pancreatic interstitium (Figure 2s). Pathologic scores were quite consistent to the microscopically gross observation (Figure $2 \mathrm{u}$ and $\mathrm{w}$ ). Levels of serum amylase were proportional to these histological findings (Figure $2 \mathrm{w}$ ).

\section{Basal Expression Levels of Spink3 in Mice under Normal Feeding}

Basal expression levels of Spink3 without induction were examined by western blot analysis in each strain of mice. Interestingly, results showed that expression of Spink3 was statistically higher in JF1 and C57BL/6J than the other three strains of mice that were susceptible to pancreatitis (Supplementary Figure 1).

\section{Expression of Spink3 and Prss1 after Treatment with Cerulein}

We examined the levels of mRNA and protein expressions of Spink3 and Prss1 without and with cerulein treatment. Without induction, CBA/J mice had lower Spink3 mRNA levels than those in other strains (Figure $3 \mathrm{a}$ and b). With cerulein treatment, Spink3 mRNA expression significantly increased in JF1, mildly in C57BL/6J, but decreased in BALB/ $\mathrm{c}$ and $\mathrm{C} 3 \mathrm{H} / \mathrm{HeJ}$ strains (Figure $3 \mathrm{a}$ and $\mathrm{c}$ ).

Without cerulein treatment, BALB/c mice had higher Prss1 mRNA levels than those in other strains (Figure $3 \mathrm{a}$ and $\mathrm{b}$ ). After cerulein treatment, Prss1 mRNA levels in JF1, C57BL/ $6 \mathrm{~J}$, and $\mathrm{BALB} / \mathrm{c}$ remained unchanged, but decreased in $\mathrm{CBA} / \mathrm{J}$ and $\mathrm{C} 3 \mathrm{H} / \mathrm{HeJ}$ mice (Figure 3a and c). Expression G3PDH was notably augmented with cerulein treatment (Figure 3a), suggesting that this gene expression could not be used as reference loading control. Thus, we used $18 \mathrm{~S}$ or $28 \mathrm{~S}$ rRNA as reference RNAs.

Then, protein expression for Spink3 and Prss1 was examined by western blot analyses. Notably, Spink3 levels in JF1 mice decreased after overnight starvation (Figure 3e) when compared with normal feeding (see Supplementary Figure 1), although levels in other strains were unchanged after starvation. Without treatment, levels of Spink3 in C57BL/6J mice were higher than those in the other four strains (Figure 3d and e). With cerulein treatment, Spink3 expression was increased significantly in JF1, moderately in C57BL/6J and $\mathrm{BALB} / \mathrm{c}$, and slightly in $\mathrm{CBA} / \mathrm{J}$ and $\mathrm{C} 3 \mathrm{H} / \mathrm{HeJ}$ (Figure $3 \mathrm{~d}$ and $\mathrm{f}$ ).

The level of Prss1 protein expression was lower in CBA/J and $\mathrm{C} 3 \mathrm{H} / \mathrm{HeJ}$ than those in the other three strains without induction (Figure $3 \mathrm{~d}$ and e). However, levels of Prss1 increased significantly in $\mathrm{BALB} / \mathrm{c}, \mathrm{CBA} / \mathrm{J}$, and $\mathrm{C} 3 \mathrm{H} / \mathrm{HeJ}$ with cerulein treatment, whereas no notable changes were observed in JF1 and C57BL/6 strains (Figure $3 \mathrm{~d}$ and f). Taken together, these results suggest that induction levels of Spink3 and Prss1 were negatively and positively related to susceptibility of cerulein-induced pancreatitis, respectively.

\section{Expression of Spink3 and Prss1 with CDE Diet}

When given a normal diet, levels of Spink3 mRNA in C57BL/ $6, \mathrm{CBA} / \mathrm{J}$, and $\mathrm{C} 3 \mathrm{H} / \mathrm{HeJ}$ mice were higher than those in JF1 and $\mathrm{BALB} / \mathrm{c}$ (Figure $4 \mathrm{a}$ and $\mathrm{b}$ ). In the $\mathrm{CDE}$ diet model, Spink3 mRNA expression was significantly increased in JF1 mice, but mildly increased in C57BL/6J and CBA/J (Figure 4a and $\mathrm{c}$ ). 



\begin{tabular}{|c|c|c|c|c|c|c|c|c|}
\hline M. Strain & Treat & $\begin{array}{c}\text { No. of } \\
\text { Mice }\end{array}$ & $E$ & H I & V & & $\begin{array}{l}\text { Total } \\
\text { Scores }\end{array}$ & Mean \pm SD \\
\hline \multirow[b]{2}{*}{$\mathrm{JF} 1 / \mathrm{Ms}$} & Saline & 5 & 2 & \begin{tabular}{c|c}
0 & 0 \\
\end{tabular} & 0 & 0 & 2 & $0.2 \pm 0.12$ \\
\hline & Cerulein & 5 & 5 & \begin{tabular}{l|l}
0 & 3 \\
\end{tabular} & 1 & 3 & 12 & $2.28 \pm 0.49$ \\
\hline \multirow{2}{*}{ C57BL/6 } & Saline & 5 & 0 & $0 \mid 0$ & 0 & 0 & 0 & $0.2 \pm 0.12$ \\
\hline & \begin{tabular}{|l|} 
Cerulein \\
\end{tabular} & 5 & 2 & $0[0$ & 0 & 0 & 2 & $0.36 \pm 0.11$ \\
\hline \multirow{2}{*}{ BALB/c } & Saline & 5 & 0 & $0 \mid 0$ & 0 & 0 & 0 & $0 \pm 0$ \\
\hline & \begin{tabular}{|l} 
Cerulein \\
\end{tabular} & 5 & 41 & & 3 & & 18 & $3.6 \pm 0.4$ \\
\hline \multirow[b]{2}{*}{ CBA/J } & Saline & 5 & 11 & 00 & 0 & 0 & 1 & $0.2 \pm 0.18$ \\
\hline & Cerulein & 5 & 52 & & 3 & & 29 & $5.8 \pm 1.02$ \\
\hline \multirow{2}{*}{$\mathrm{C} 3 \mathrm{H} / \mathrm{He}$} & \begin{tabular}{|l|} 
Saline \\
\end{tabular} & 5 & 2 & 0 & 0 & 0 & 2 & $0.2 \pm 0.07$ \\
\hline & \begin{tabular}{|l|} 
Cerulein \\
\end{tabular} & 5 & 7 & 19 & & 20 & 38 & $7.6 \pm 0.8$ \\
\hline
\end{tabular}
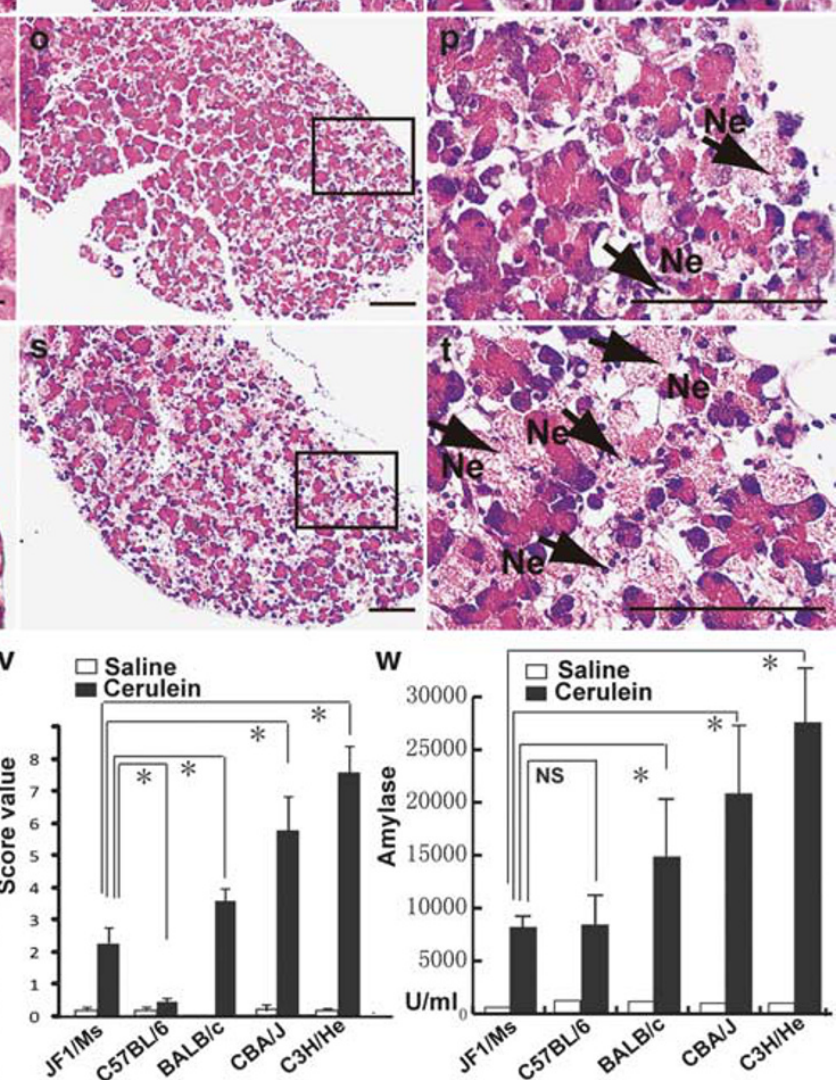

Figure 1 Histological changes, pathologic scores, and serum amylase levels in pancreas with and without cerulein treatment. (a, $\mathbf{b}, \mathbf{e}, \mathbf{f}, \mathbf{i}, \mathbf{j}, \mathbf{m}, \mathbf{n}, \mathbf{q}, \mathbf{r})$ Saline-treated mice. (c, d, $\mathbf{g}, \mathbf{h}, \mathbf{k}, \mathbf{l}, \mathbf{0}, \mathbf{p}, \mathbf{s}, \mathbf{t})$ Cerulein-treated mice. (b, d, $\mathbf{f}, \mathbf{h}, \mathbf{j}, \mathbf{l}, \mathbf{n}, \mathbf{p}, \mathbf{r}, \mathbf{t})$ Higher magnification of areas indicated in (a, c, e, $\mathbf{g}, \mathbf{i}, \mathbf{k}, \mathbf{m}, \mathbf{0}, \mathbf{q}, \mathbf{s})$, (u) Pathologic scores calculated based on five parameters: edema (E), hemorrhage (H), infiltrates (I), vacuolization (V), necrosis $(\mathrm{N})$ of acinar cells. (t) Scores: total scores derived from the evaluation of five parameters. (v) Column graph of pathologic scores shown as mean \pm s.d. (error bar). (w) Serum amylase levels. Black arrows indicate respective inflammatory changes. Scale bar: $50 \mu \mathrm{m}$. ${ }^{\star} P<0.05$. NS: no significance. 


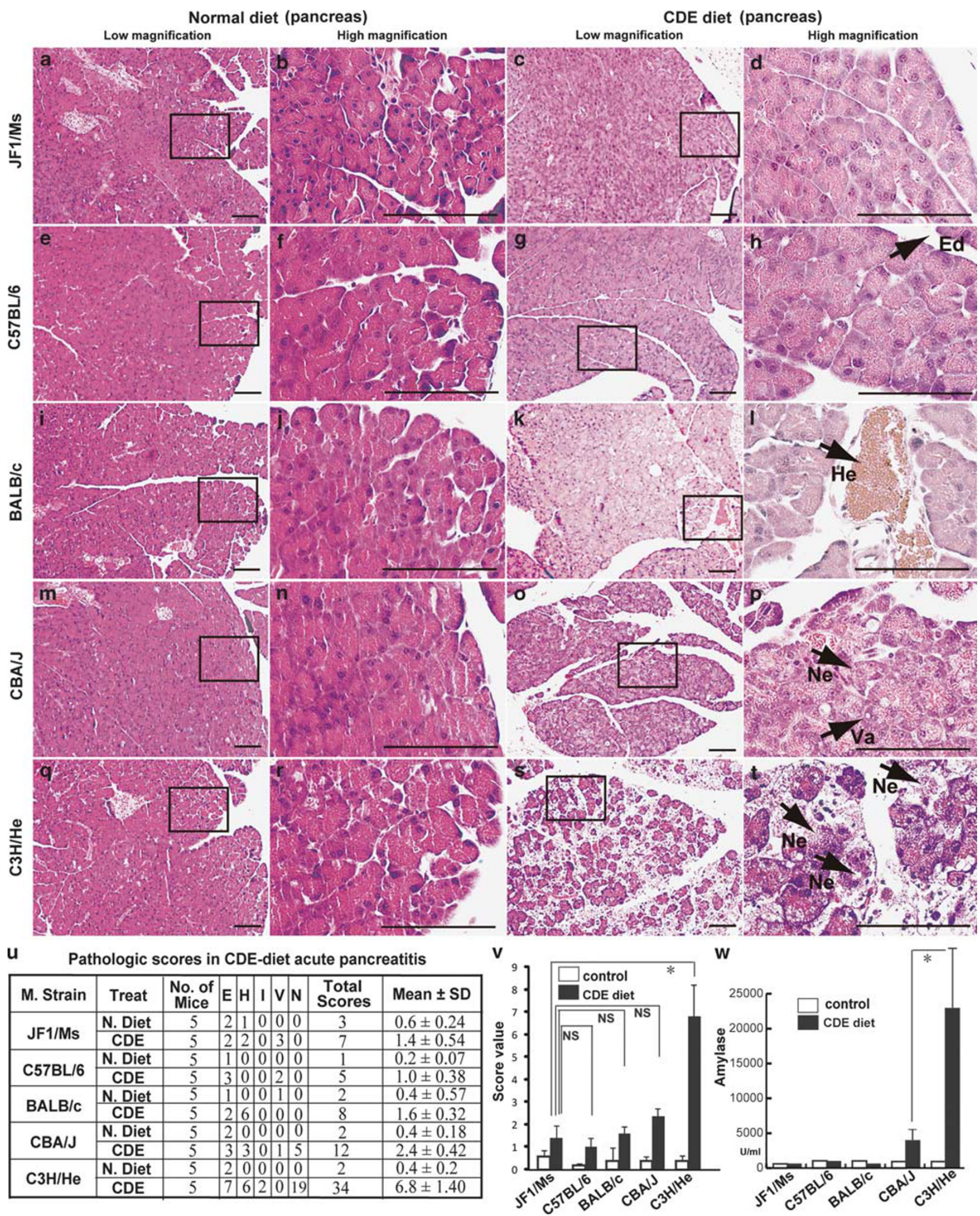

Figure 2 Histological changes, pathologic scores, and serum amylase levels in pancreas with and without CDE diet-induced acute pancreatitis.

$(\mathbf{a}, \mathbf{b}, \mathbf{e}, \mathbf{f}, \mathbf{i}, \mathbf{j}, \mathbf{m}, \mathbf{n}, \mathbf{q}, \mathbf{r})$ Saline-treated mice. (c, $\mathbf{d}, \mathbf{g}, \mathbf{h}, \mathbf{k}, \mathbf{l}, \mathbf{0}, \mathbf{p}, \mathbf{s}, \mathbf{t})$ Cerulein-treated mice. (b, $\mathbf{d}, \mathbf{f}, \mathbf{h}, \mathbf{j}, \mathbf{l}, \mathbf{n}, \mathbf{p}, \mathbf{r}, \mathbf{t})$ Higher magnification of areas indicated in $(\mathbf{a}, \mathbf{c}, \mathbf{e}, \mathbf{g}, \mathbf{i}, \mathbf{k}, \mathbf{m}, \mathbf{0}, \mathbf{q}, \mathbf{s})$. (u) Pathologic scores calculated based on five parameters: edema (E), hemorrhage $(H)$, infiltrates (I), vacuolization $(\mathrm{V})$, necrosis (N) of acinar cells. (v) Column graph of the pathologic scores shown as mean \pm s.d. (error bar). (w) Serum amylase levels. Black arrows indicate respective inflammatory changes. Scale bar: $50 \mu \mathrm{m}$. ${ }^{\star} P<0.05$. NS: no significance. 
a



d

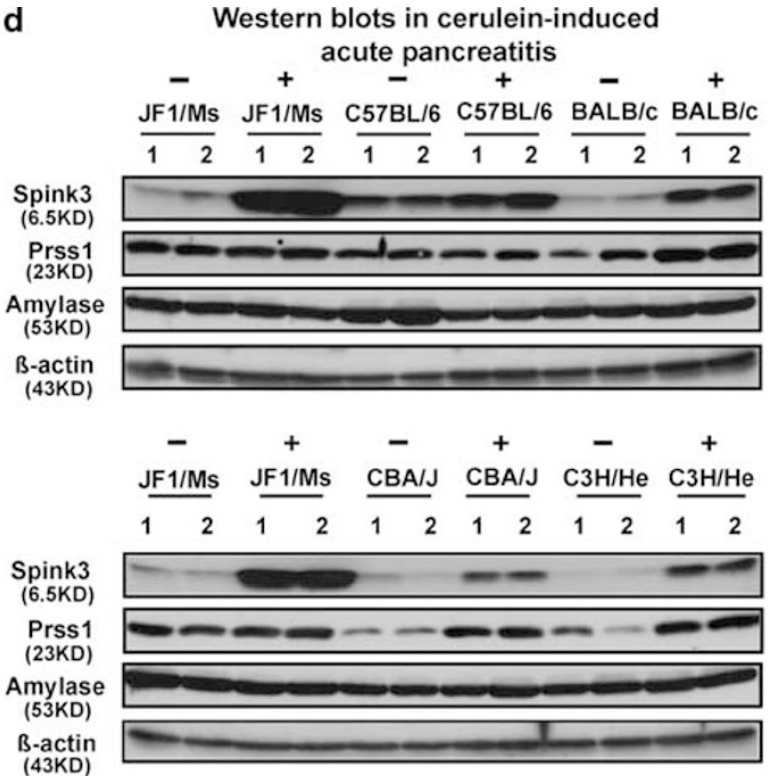

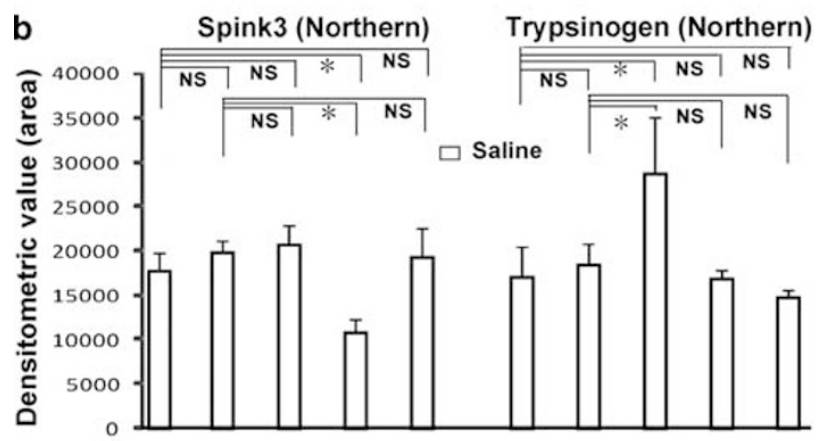
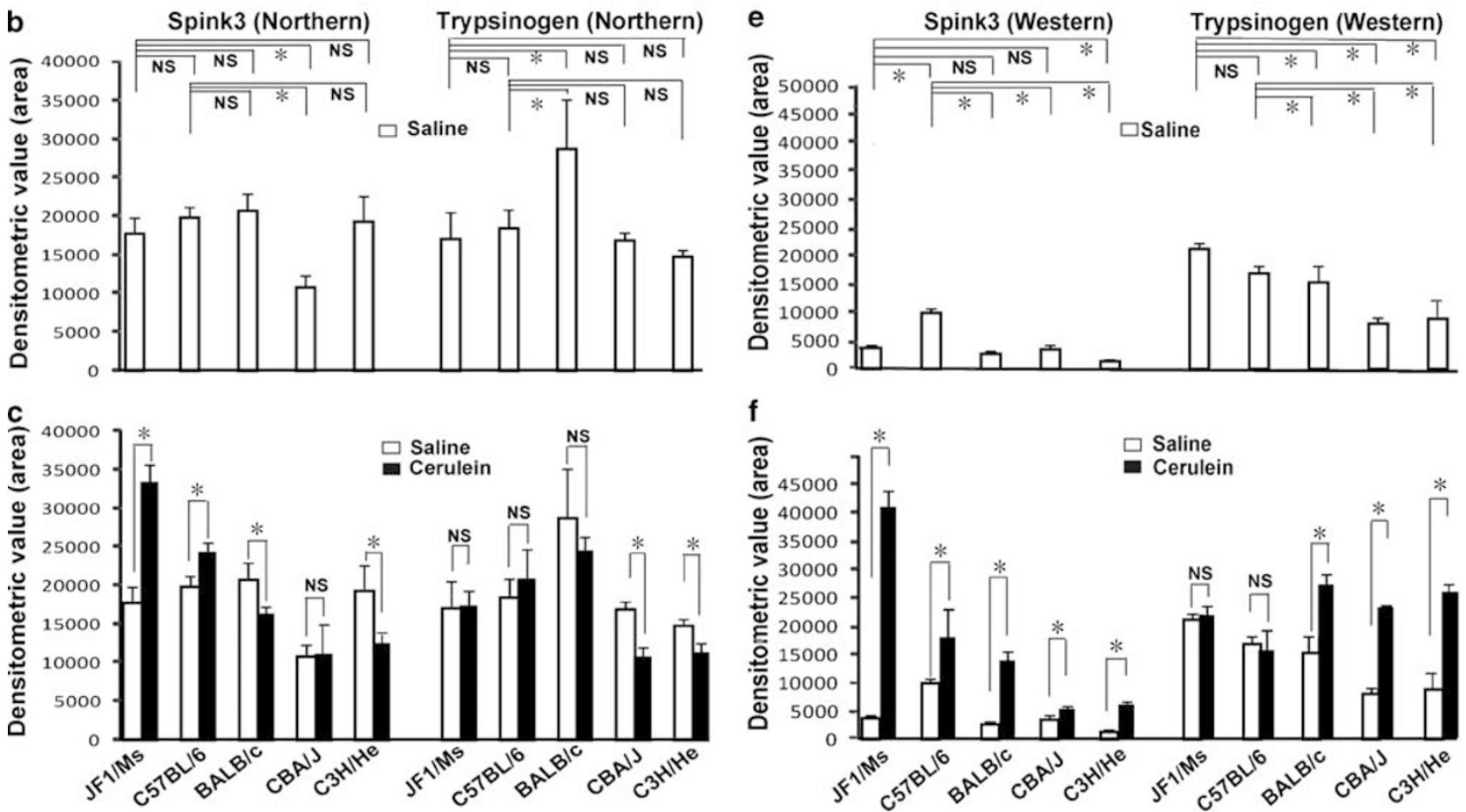

Figure 3 Northern and western blots analyses on Spink3, Prss1, and amylase expressions in cerulein-induced acute pancreatitis. (a) Northern blot analysis; $18 \mathrm{~S}$ and $28 \mathrm{~S}$ were used as loading controls because G3PDH expression was induced by cerulein treatment. The same JF1 samples were arranged in the first four lanes of northern blots. (b) Densitometric analysis for Spink3 and Prss1 expressions without cerulein induction in northern blot. (c) Densitometric analysis for Spink3 and Prss1 expressions with cerulein induction in northern blot. (d) Western blot analysis. $\beta$-actin was used as a loading control. The same JF1 samples were arranged in the first four lanes of western blots. (e) Densitometric analysis for Spink3 and Prss1 expressions after cerulein induction in western blot. (f) Densitometric analysis for Spink3 and Prss1 expressions with cerulein induction in western blot. Unfilled bars represent untreated strains of mice, whereas black bars indicate the treated strains. ' $-{ }^{\prime}$ : saline treatment. ' + ': cerulein treatment. ${ }^{\star} P<0.05$. NS: no significance.

Levels of Prss1 mRNA in JF1 and C57BL/6 strains were lower than those in other strains under a normal diet (Figure $5 \mathrm{a}$ and $\mathrm{b})$. After CDE diet, levels of Prss1 mRNA were decreased in $\mathrm{C} 57 \mathrm{BL} / 6, \mathrm{BALB} / \mathrm{c}, \mathrm{CBA} / \mathrm{J}$, and $\mathrm{C} 3 \mathrm{H} / \mathrm{HeJ}$ mice
(Figure 4a and c). Protein expression for Spink3 and Prss1 was examined by western blot analyses. Under normal diet, the levels of Spink3 were again higher in JF1 and C57BL/6J than those in other three strains (Figure $4 \mathrm{~d}$ and e). After CDE 


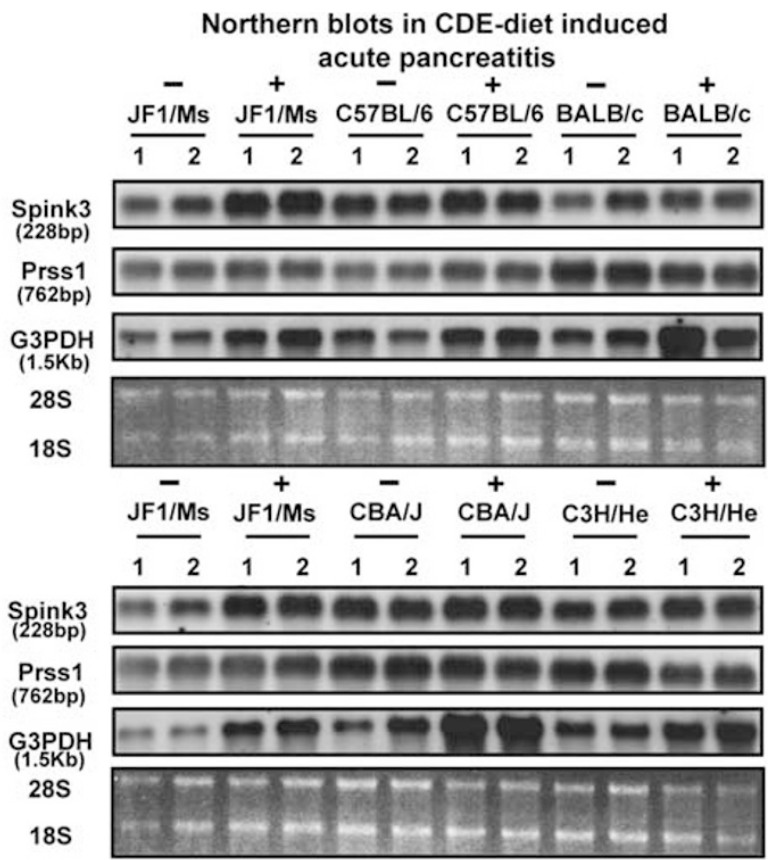

b

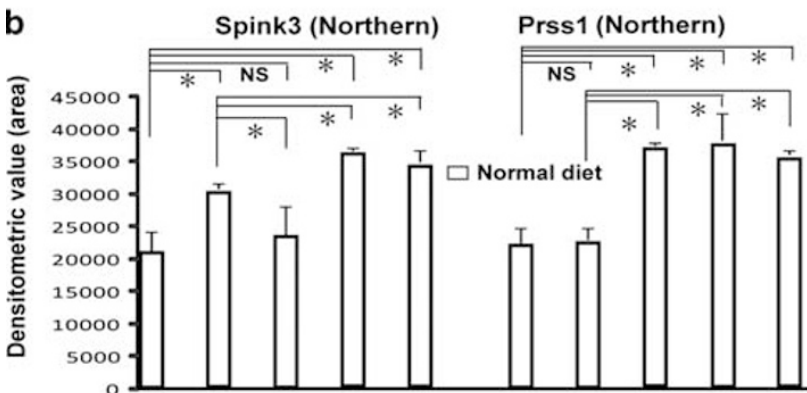

C



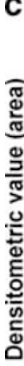



d

Western blots in CDE-diet induced acute pancreatitis

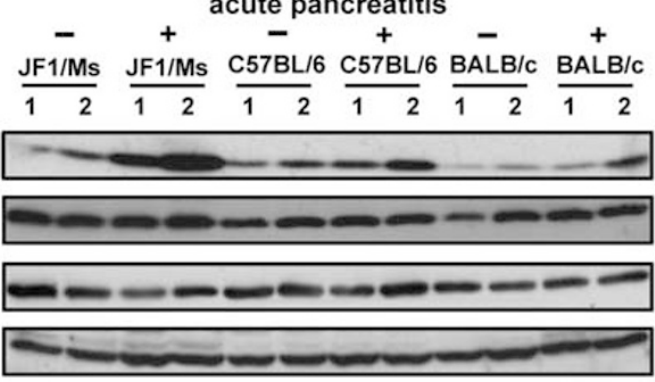

$\mathrm{B}-\mathrm{actin}$
$(43 \mathrm{KD})$



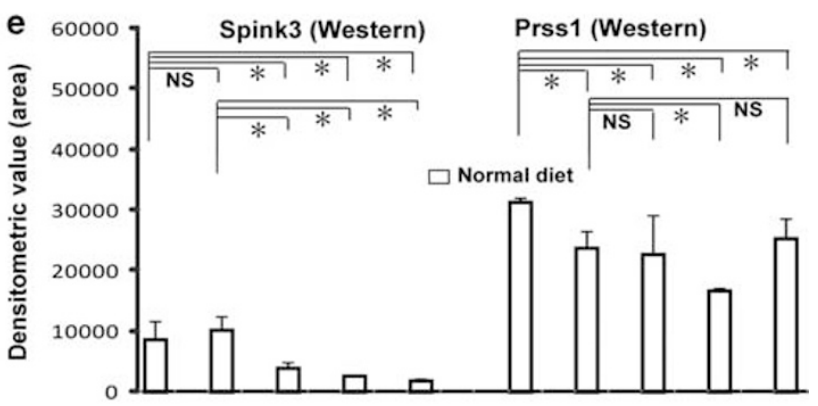

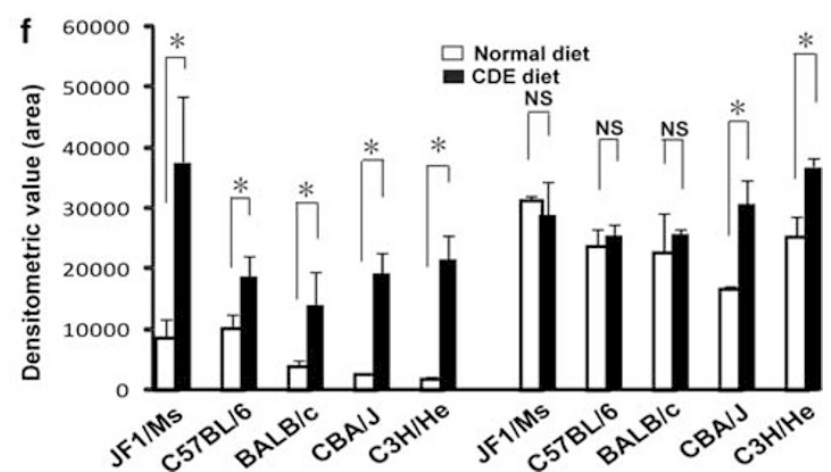

Figure 4 Northern and western blot analyses on Spink3, Prss1, and amylase expressions in CDE diet-induced acute pancreatitis. (a) Northern blot analysis; $18 \mathrm{~S}$ and $28 \mathrm{~S}$ were used as loading controls because G3PDH expression was induced by cerulein treatment. The same JF1 samples were arranged in the first four lanes of northern blots. (b) Densitometric analysis for Spink3 and Prss1 expressions without CDE diet in northern blot. (c) Densitometric analysis for Spink3 and Prss1 expressions with CDE diet in northern blot. (d) Western blot analysis. $\beta$-actin was used as a loading control. The same JF1 samples were arranged in the first four lanes of western blots. (e) Densitometric analysis for Spink3 and Prss1 expressions without CDE diet in western blot. (f) Densitometric analysis for Spink3 and Prss 1 expressions with CDE diet in western blot. Unfilled bars represent untreated strains of mice, whereas black bars indicate the treated strains. ${ }^{*} P<0.05$. NS: no significance.

diet, Spink3 expression increased significantly in JF1, but moderately in other strains (Figure $4 \mathrm{~d}$ and $\mathrm{f}$ ).

The level of Prss1 protein expression was lower in CBA/J than those in other four strains without CDE diet (Figure 4d and e). With CDE diet, Prss1 expression increased sig- nificantly in $\mathrm{CBA} / \mathrm{J}$ and $\mathrm{C} 3 \mathrm{H} / \mathrm{HeJ}$, whereas expression remained unchanged in JF1, C57BL/6J, and $\mathrm{BALB} / \mathrm{c}$ mice (Figure $4 \mathrm{~d}$ and $\mathrm{f}$ ). These results also suggest that the induction levels of Spink3 and Prss1 are negatively and positively related to susceptibility of CDE-induced pancreatitis, respectively. 


\section{Trypsin activity in cerulein-induced acute pancreatitis}

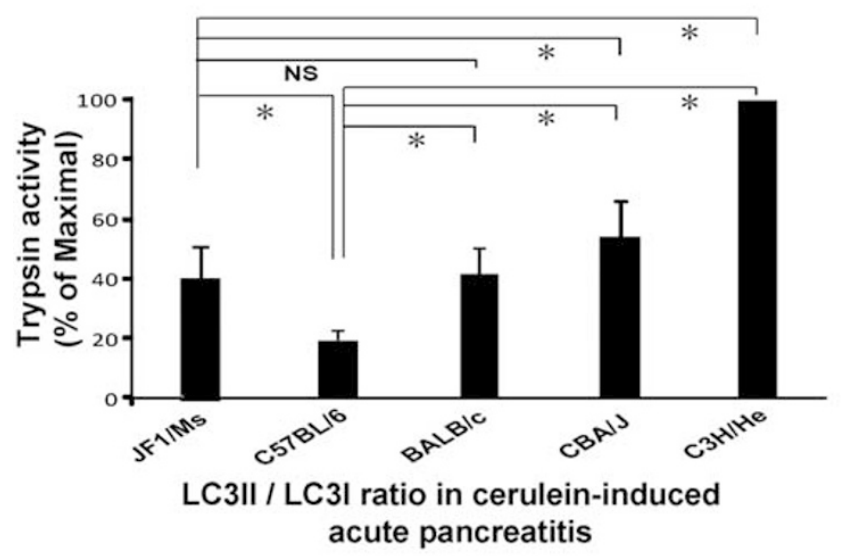

Trypsin activity in CDE-diet induced acute pancreatitis

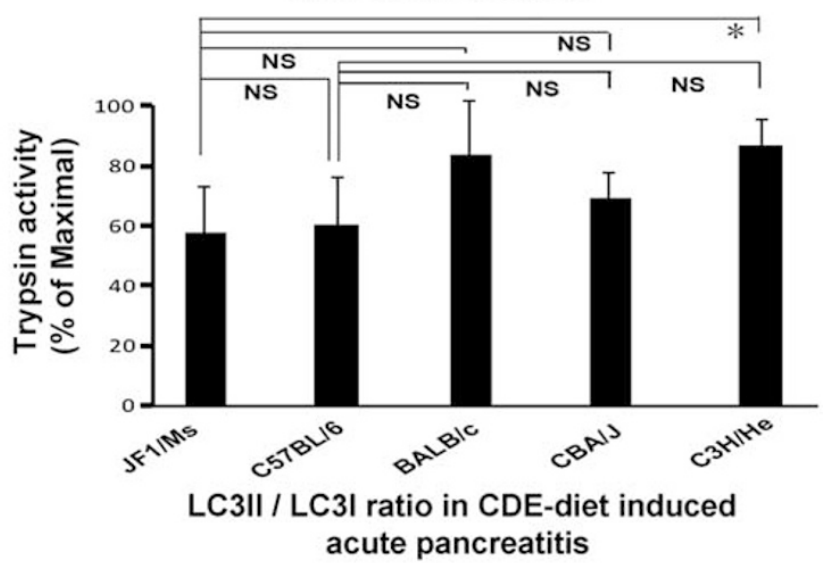


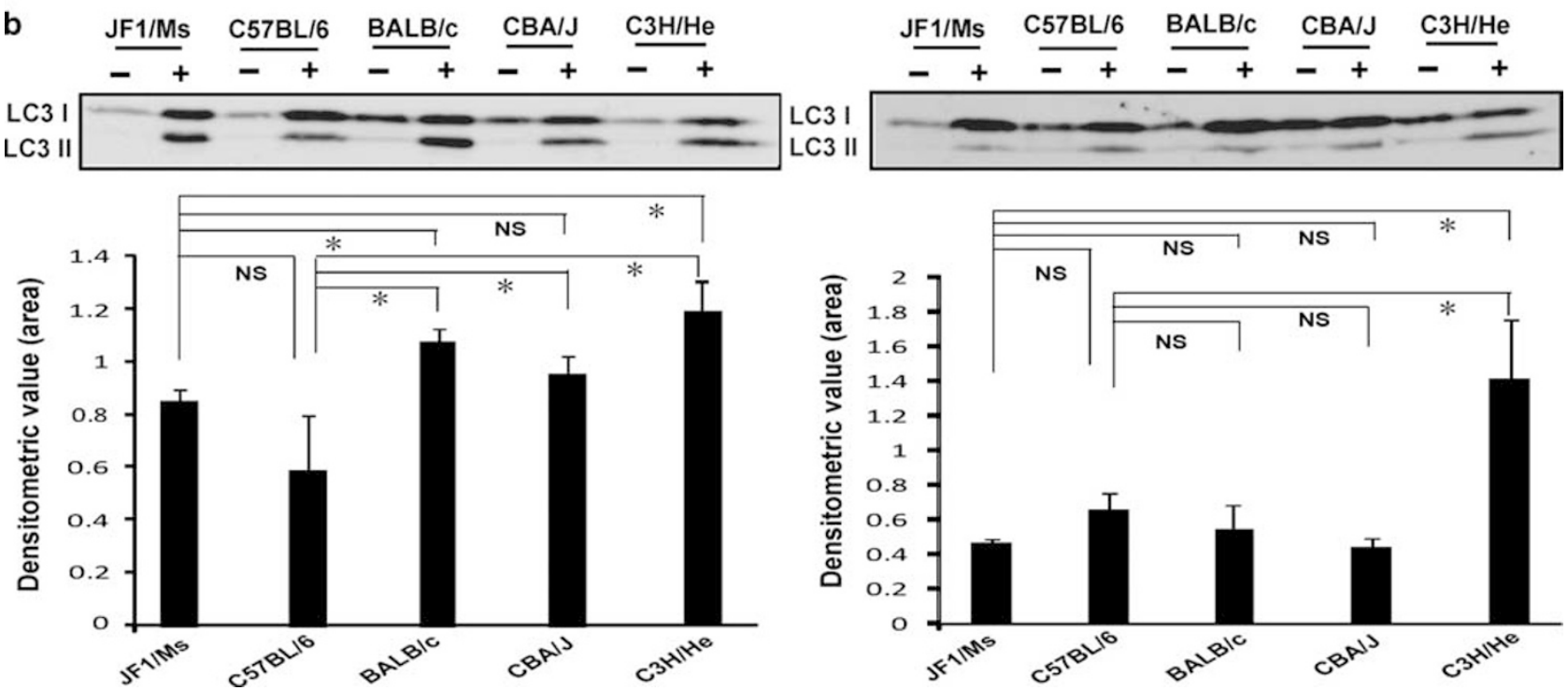

Figure 5 Trypsin activity and LC3-II expression. (a) Trypsin activity in cerulein-induced and CDE-diet-induced acute pancreatitis. Trypsin activity coincided with protein expression level of Prss1. (b) LC3-II/LC3-I ratio in cerulein-induced and CDE diet-induced acute pancreatitis. LC3-II levels were inversely related to Spink3 levels when treated with cerulein, suggesting the function of Spink3 as an inhibitor of autophagy.

\section{Trypsin Activity}

As activation or extent of trypsinogen to trypsin during initiation of acute pancreatitis is associated with the severity of acinar cell injury, we examined the trypsin activity level within pancreatic tissue homogenates among five mouse strains. The highest activity was shown in $\mathrm{C} 3 \mathrm{H} / \mathrm{HeJ}$, followed by $\mathrm{CBA} / \mathrm{J}$, $\mathrm{BALB} / \mathrm{c}$, JF1, whereas C57BL/6J displayed the lowest value in cerulein-induced pacreatitis (Figure 5a, left panel). In CDE diet, trypsin activity level was significantly higher in $\mathrm{C} 3 \mathrm{H} / \mathrm{HeJ}$ than those in other strains (Figure 5a, right panel). Not surprisingly, the variation of trypsin activity was consistent with the expression pattern of trypsinogen among the five mouse strains.

\section{Expression of LC3, an Autophagic Indicator}

To approve that Spink3 functions also as a suppressor of autophagy, we checked in the five mouse strains the expres- sion level of microtubule-associated protein 1 LC3. As LC3-I is converted into LC3-II during autophagosome formation, we determined the LC3-II/LC3-I ratio by densitometric analysis. As shown in Figure 5b, the ratio was higher in $\mathrm{C} 3 \mathrm{H} /$ $\mathrm{HeJ}, \mathrm{BALB} / \mathrm{c}$, and $\mathrm{CBA} / \mathrm{J}$ than that in JF1 and C57BL/6J when treated with cerulein, showing that the mouse strain with higher Spink3 expression possessed low level of LC3-II, meaning less severe degree of autophagy.

\section{Nucleotide Sequences of Prss 1 and Spink3 cDNAs}

To examine whether there was any nucleotide changes in coding regions of the Prss 1 and Spink 3 genes, we sequenced cDNA of these two genes isolated from all five strains. Nucleotide sequences of Prss1 and Spink3 cDNAs were exactly the same in four strains of mice: C57BL/6J, CBA/J, $\mathrm{BALB} / \mathrm{c}$, and $\mathrm{C} 3 \mathrm{H} / \mathrm{HeJ}$. In contrast, in the $807 \mathrm{bp}$ of the Prss 1 
Table 1 Single-nucleotide polymorphisms in JF1 cDNA vs B6

\begin{tabular}{|c|c|c|c|c|c|}
\hline \multicolumn{3}{|c|}{ Prss1 (807 bp) } & \multicolumn{3}{|c|}{ Spink3 (284 bp) } \\
\hline Position & Nucleotide change & Amino-acid change & Position & Nucleotide change & Amino-acid change \\
\hline Exon 1 & $15 G>C$ & No & Exon 3 & $192 \mathrm{G}>\mathrm{A}$ & No \\
\hline Exon 3 & $342 \mathrm{~A}>\mathrm{T}$ & No & Exon 3 & $198 \mathrm{C}>\mathrm{T}$ & No \\
\hline Exon 4 & $516 G>A$ & No & Exon 4 & $279 A>G$ & No \\
\hline Exon 4 & $568 \mathrm{G}>\mathrm{A}$ & E190K & & & \\
\hline
\end{tabular}

JF1, Japanese Fancy Mouse 1. E190A, substitution of the glutamic acid (E) at amino-acid position 190 with lysine (K).

cDNA sequence of JF1 mice, five nucleotide changes were found (Table 1). However, only the alteration, G to A at position 568, resulted in substitution of glutamic acid with lysine at amino-acid position 190 (Table 1). On the other hand, three nucleotide changes were found within the $284 \mathrm{bp}$ region of Spink 3 cDNA of JF1 mice without an amino-acid substitution (Table 1).

\section{Nucleotide Sequences of $\mathbf{3} \mathbf{k b}$ Upstream Regions of Spink3 and Prss1 Genes}

As expression patterns of Spink3 and Prss1 differed among mouse strains, we sequenced the approximately $3 \mathrm{~kb}$ promoter regions of Spink3 and Prss 1 genes. We chose JF1 and $\mathrm{C} 3 \mathrm{H} / \mathrm{HeJ}$ as representatives of resistant and susceptible mouse strains, respectively. As the most conserved binding sites for transcription factors in pancreas-specific genes reside within the $1 \mathrm{~kb}$ upstream region, we focused on the $3 \mathrm{~kb}$ upstream regions of both Spink3 and Prss1 genes in this study. All of the sequence data were aligned and compared with the corresponding public database for $\mathrm{C} 57 \mathrm{BL} / 6 \mathrm{~J}$ mice. For the upstream nucleotide sequence of the Spink3 gene, eight nucleotide changes $(8 / 3000=0.27 \%)$ were found in $\mathrm{C} 3 \mathrm{H} / \mathrm{HeJ}$ vs $\mathrm{C} 57 \mathrm{BL} / 6 \mathrm{~J}$, whereas 92 nucleotide changes $(92 / 3000=3.07 \%)$ appeared in JF1 vs C57BL/6J mice, representing a huge difference in the $3 \mathrm{~kb}$ upstream of the transcription start site in JF1 mice (Supplementary Figure 2). Notably, almost half of nucleotide changes ${ }^{30}$ were found within the $1 \mathrm{~kb}$ upstream region in JF1 (Supplementary Figure 2). Several conserved motifs for transcription factors $^{31-36}$ were found in the $3 \mathrm{~kb}$ upstream regions of Spink3 genes as summarized in Supplementary Figure 2. Interestingly, an additional $10 \mathrm{bp}$ was found between -372 and -381 in JF1 mice, although a conserved motif has not been reported around this region.

With respect to the Prss1 gene, $46(46 / 3000=1.53 \%)$ or 39 $(39 / 3000=1.30 \%)$ nucleotide changes were identified in $\mathrm{C} 3 \mathrm{H} / \mathrm{He}$ or JF1 strains against C57BL/6J mice, respectively (Supplementary Figure 3). However, the region between -3000 and $-2300 \mathrm{bp}$ of C57BL/6J was the same as that of $\mathrm{JF} 1$, but not of $\mathrm{C} 3 \mathrm{H}$. On the other hand, the region between -2300 and $-1 \mathrm{bp}$ of $\mathrm{C} 57 \mathrm{BL} / 6 \mathrm{~J}$ mice was similar to that of $\mathrm{C} 3 \mathrm{H}$ mice. Three binding sites were found in the $1 \mathrm{~kb}$ upstream region of the Prss1 gene ${ }^{31,37}$ (Supplementary Figure 3). All these sequences are identical in all strains except one nucleotide change at -192 of the binding site (ATCACCTGCT) for nuclear protein in JF1 mice.

\section{DISCUSSION}

In this study, we showed strain differences using two models of experimental acute pancreatitis and identified a negative and positive relationship regarding the expression levels of Spink3 and Prss1, respectively, in the susceptibility to experimental acute pancreatitis. In addition, we showed that sequence differences in the promoter region of the Spink3 gene was significant between JF1 and other laboratory mouse strains, suggesting that differences in gene regulation are connected to a susceptibility to induced acute pancreatitis.

Pathologically, there were qualitative differences between cerulein- and CDE diet-induced pancreatitis in addition to the severity of pancreatitis. In the CDE diet model, much more hemorrhagic legions were noticed, as has been reported before. ${ }^{28}$ This difference may be caused by different induction mechanisms in the early stages of acute pancreatitis. Cerulein is a cholecystokinin analog that can stimulate pancreatic acinar cells to secrete digestive enzymes. In supramaximal stimulation by cerulein, secretory activity increases dramatically, but membrane recruitment is insufficient for a strong demand of zymogen granule membrane, resulting in an inhibition of exocytosis at the luminal plasma membrane. On the other hand, a more likely target of ethionine is phospholipid metabolism of membranes that are involved in the processes of intracellular transport and secretion of pancreatic enzymes. Feeding a choline-deficient diet potentiated the activity of ethionine, because a choline-deficient diet also induced changes in membrane phospholipids of cellular organelles. ${ }^{38-40}$ Although the detailed mechanism for hemorrhagic lesions remains unclear, destruction of the elastic tissue of the intrapancreatic vessels may also occur in such a situation.

In two experimental models, we observed similar strain differences in disease susceptibility, which were most severe in $\mathrm{C} 3 \mathrm{H} / \mathrm{HeJ}$ and $\mathrm{CBA} / \mathrm{J}$ strains, moderate in $\mathrm{BALB} / \mathrm{c}$ mice, 
and mildest in C57BL/6J and JF1 strains. In human beings, a relationship between the PRSS1 gene mutations and the onset of pancreatitis has been established by many investigations. ${ }^{21,30,41,42}$ Thus, it is possible that differences in primary structure or expression of the Prss1 gene are responsible for strain differences. Although we found one single-nucleotide polymorphism (SNP) in exon 4 that resulted in substitution of glutamic acid with lysine at amino-acid position 190 in JF1 mice, this mutation was not observed in the PRSS1 gene of human patients, suggesting that the coding region of the Prss1 gene is not related to the susceptibility to pancreatitis among these strains.

Interestingly, Prss1 protein expression was obviously increased in $\mathrm{BALB} / \mathrm{c}, \mathrm{CBA} / \mathrm{J}$, and $\mathrm{C} 3 \mathrm{H} / \mathrm{HeJ}$ mice, but not in JF1 and C57BL/6J mice with cerulein treatment. This high Prss1 expression coincided with a high trypsin activity. Many nucleotide changes found in the $3 \mathrm{~kb}$ upstream region of the Prss1 gene among C57BL/6J, C3H/HeJ, and JF1 strains may be responsible for different expression level.

Differences in the primary structure or expression of the Spink3 gene may also be involved in susceptibility to the development of pancreatitis. However, we could not find any SNPs with an amino-acid substitution between JF1 and other strains of mice. Thus, the coding region of the Spink3 gene was not related to pancreatitis susceptibility. Meaningfully, we found a significantly higher expression of Spink3 in JF1 and C57BL/6J mice under normal feeding (Figure $3 a$ and $b$ ). Furthermore, Spink3 expression was strongly augmented in JF1 mice with cerulein treatment. This high Spink3 expression was associated with low level of LC3-II expression, implying the function of Spink3 as an inhibitor of autophagy. As shown in Supplementary Figure 2, we found significant nucleotide changes in the $3 \mathrm{~kb}$ upstream region of the Spink3 gene of JF1 mice. It is of interest that an additional $10 \mathrm{bp}$ was inserted between -372 and -381 region in JF1 mice, although a conserved motif has not been reported around this region. Therefore, this region might be involved in the regulation of gene expression under cerulein stimulation. Taking these into account, the mechanisms by which Prss1 and Spink3 might be influencing the susceptibility are proposed here in a molecular model shown in Figure 6. In resistant strains, increased Spink3 expression caused by cerulein or CDE diet suppresses autophagy, leading to reduced activation of trypsinogen. In addition, Spink3 can bind to trypsin to inhibit its activity directly. Thus, both enhanced Spink 3 and low Prss1 expression result in reduced trypsin activity, leading to less severe acute pancreatitis. In susceptible strains, low level of Spink3 expression results in enhanced autophagy, causing the conversion of trypsinogen to trypsin, and in low-level inhibition of trypsin. Thus, both high Prss1 and low Spink3 expressions result in increased trypsin activity, leading to more severe acute pancreatitis.

After activation of trypsinogen, inflammation is eventually induced in both models. Therefore, different responses in inflammatory factors, such as NF- $\kappa \mathrm{B}$, TNF- $\alpha$, IL-1,

\section{Resistant strain}



Susceptible strain

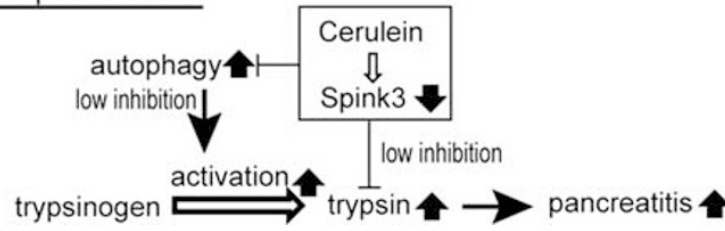

Figure 6 Proposed model for the function of Prss1 and/or Spink3 on susceptibility of acute pancreatitis. In resistant strains, increased Spink3 expression caused by cerulein suppresses autophagy, and trypsin activity, leading to less severe acute pancreatitis. In susceptible strains, low expression of Spink3 and high expression of Prss1 result in enhanced autophagy, causing the conversion of trypsinogen to trypsin and in lowlevel inhibition of trypsin, thus leading to more severe acute pancreatitis.

Heat Shock Protein, NO, or TLR4, among strains may be involved in pancreatitis susceptibility. Actually, inflammatory responses are different from one strain to another and a given strain can have variable inflammatory responses from one form of damage to another. For example, inbred mice varied significantly in their susceptibility to cigarette smokeinduced emphysema. ${ }^{43,44}$ Further studies will be required to analyze genetic mechanisms for differences in inflammatory responses.

Advances in molecular physiology indicate the mouse to be an ideal investigative model to determine genomic variants that affect susceptibility to disease. This model offers the advantage of studying a large number of genetically identical animals under controlled conditions. Animal studies complement human studies by introducing an experimental control and the opportunity to pursue functional genomics and expression studies at the level of organs, tissues, or cells. Molecular mechanisms for disease resistance/susceptibility may differ among strains, and the JF1 strain may give a unique opportunity to examine such mechanisms that may not be found in other laboratory mouse strains.

Supplementary Information accompanies the paper on the Laboratory Investigation website (http://www.laboratoryinvestigation.org)

\section{ACKNOWLEDGEMENTS}

We herein sincerely appreciate the excellent work on the tissue sectioning preparation by Mrs Michiyo Nakata and Ms Yumi Otake. We also thank the Riken BioResource Center, Tsukuba, Japan for supplying JF1 mice. This work was supported in part by KAKENHI (Grant-in-Aid for Scientific Research) in Priority Areas 'Integrative Research Toward the Conquest of Cancer' (17012018) from the Ministry of Education, Culture, Sports, Science, and Technology, a Grant-in-Aid for Scientific Research (S) (21220010) and a Grant-in-Aid for Young Scientists (B) (18790968) from the Japan Society for the Promotion of Science (JSPS) of Japan. 


\section{DISCLOSURE/CONFLICT OF INTEREST}

The authors declare no conflict of interest.

1. Beck JA, Lloyd S, Hafezparast M, et al. Genealogies of mouse inbred strains. Nat Genet 2000;24:23-25.

2. Moore KJ. Utilization of mouse models in the discovery of human disease genes. Drug Discov Today 1999;4:123-128.

3. Yonekawa $\mathrm{H}$, Moriwaki $\mathrm{K}$, Gotoh $\mathrm{O}$, et al. Hybrid origin of Japanese mice 'Mus musculus molossinus': evidence from restriction analysis of mitochondrial DNA. Mol Biol Evol 1988;5:63-78.

4. Prager EM, Orrego C, Sage RD. Genetic variation and phylogeography of central Asian and other house mice, including a major new mitochondrial lineage in Yemen. Genetics 1998;150:835-861.

5. Wade CM, Kulbokas III EJ, Kirby AW, et al. The mosaic structure of variation in the laboratory mouse genome. Nature 2002;420:574-578.

6. Sakai T, Miura I, Yamada-Ishibashi $S$, et al. Update of mouse microsatellite database of Japan (MMDBJ). Exp Anim 2004;53:151-154.

7. Abe $\mathrm{K}$, Noguchi $\mathrm{H}$, Tagawa $\mathrm{K}$, et al. Contribution of Asian mouse subspecies Mus musculus molossinus to genomic constitution of strain $\mathrm{C} 57 \mathrm{BL} / 6 \mathrm{~J}$, as defined by BAC-end sequence-SNP analysis. Genome Res 2004;14:2439-2447.

8. Jansa P, Divina P, Forejt J. Construction and characterization of a genomic BAC library for the Mus $\mathrm{m}$. musculus mouse subspecies (PWD/Ph inbred strain). BMC Genomics 2005;6:161.

9. Moriwaki K. Wild mouse from geneticist's viewpoint. In: Moriwaki K, Shiroishi T, Yonekawa H (eds). Genetics in Wild Mice: Its Application to Biomedical Research. Japan Scientific Press/Karger: Tokyo, 1994, pp xiii-xxiv.

10. Koide $\mathrm{T}$, Moriwaki $\mathrm{K}$, Uchida $\mathrm{K}$, et al. A new inbred strain JF1 established from Japanese fancy mouse carrying the classic piebald allele. Mamm Genome 1998;9:15-19.

11. Surwit RS, Kuhn CM, Cochrane $C$, et al. Diet-induced type II diabetes in C57BL/6J mice. Diabetes 1988;37:1163-1167.

12. Kobayashi M, Ohno T, Tsuchiya T, et al. Characterization of diabetesrelated traits in MSM and JF1 mice on high-fat diet. J Nutr Biochem 2004;15:614-621.

13. Gukovskaya AS, Hosseini S, Satoh A, et al. Ethanol differentially regulates NF-kappaB activation in pancreatic acinar cells through calcium and protein kinase $C$ pathways. Am J Physiol Gastrointest Liver Physiol 2004;286:G204-G213.

14. Pandol SJ. Acute pancreatitis. Curr Opin Gastroenterol 2005;21: 538-543.

15. Satoh A, Gukovskaya AS, Reeve Jr JR, et al. Ethanol sensitizes NF-kappaB activation in pancreatic acinar cells through effects on protein kinase C-epsilon. Am J Physiol Gastrointest Liver Physiol 2006;291:G432-G438.

16. Schenker S, Montalvo R. Alcohol and the pancreas. Recent Dev Alcohol 1998;14:41-65.

17. Acosta JM, Ledesma CL. Gallstone migration as a cause of acute pancreatitis. N Engl J Med 1974;290:484-487.

18. Lerch MM, Hernandez CA, Adler G. Gallstones and acute pancreatitismechanisms and mechanics. Dig Dis 1994;12:242-247.

19. Rosendahl J, Bodeker H, Mossner J, et al. Hereditary chronic pancreatitis. Orphanet J Rare Dis 2007;2:1.

20. Hirota $\mathrm{M}$, Ohmuraya $\mathrm{M}$, Baba $\mathrm{H}$. Genetic background of pancreatitis. Postgrad Med J 2006;82:775-778.

21. Whitcomb DC, Gorry MC, Preston RA, et al. Hereditary pancreatitis is caused by a mutation in the cationic trypsinogen gene. Nat Genet 1996;14:141-145.

22. Varallyay E, Pal G, Patthy A, et al. Two mutations in rat trypsin confer resistance against autolysis. Biochem Biophys Res Commun 1998;243:56-60
23. Witt $\mathrm{H}$, Luck W, Hennies $\mathrm{HC}$, et al. Mutations in the gene encoding the serine protease inhibitor, Kazal type 1 are associated with chronic pancreatitis. Nat Genet 2000;25:213-216.

24. Ohmuraya M, Hirota M, Araki K, et al. Enhanced trypsin activity in pancreatic acinar cells deficient for serine protease inhibitor kazal type 3. Pancreas 2006;33:104-106.

25. Hashimoto $D$, Ohmuraya $M$, Hirota $M$, et al. Involvement of autophagy in trypsinogen activation within the pancreatic acinar cells. J Cell Biol 2008;181:1065-1072.

26. Ohmuraya M, Yamamura K. Autophagy and acute pancreatitis: a novel autophagy theory for trypsinogen activation. Autophagy 2008;4: 1060-1062.

27. Rosendahl J, Witt H, Szmola R, et al. Chymotrypsin C (CTRC) variants that diminish activity or secretion are associated with chronic pancreatitis. Nat Genet 2008;40:78-82.

28. Lombardi B, Estes LW, Longnecker DS. Acute hemorrhagic pancreatitis (massive necrosis) with fat necrosis induced in mice by DL-ethionine fed with a choline-deficient diet. Am J Pathol 1975;79:465-480.

29. Schmidt J, Lewandrowski K, Fernandez-del Castillo C, et al. Histopathologic correlates of serum amylase activity in acute experimental pancreatitis. Dig Dis Sci 1992;37:1426-1433.

30. Nishimori I, Kamakura M, Fujikawa-Adachi K, et al. Mutations in exons 2 and 3 of the cationic trypsinogen gene in Japanese families with hereditary pancreatitis. Gut 1999;44:259-263.

31. Boulet AM, Erwin CR, Rutter WJ. Cell-specific enhancers in the rat exocrine pancreas. Proc Natl Acad Sci USA 1986;83:3599-3603.

32. Cockell M, Stevenson BJ, Strubin $M$, et al. Identification of a cell-specific DNA-binding activity that interacts with a transcriptional activator of genes expressed in the acinar pancreas. Mol Cell Biol 1989;9: 2464-2476.

33. Roux E, Strubin M, Hagenbuchle $O$, et al. The cell-specific transcription factor PTF1 contains two different subunits that interact with the DNA. Genes Dev 1989;3:1613-1624.

34. Stevenson BJ, Hagenbuchle O, Wellauer PK. Sequence organisation and transcriptional regulation of the mouse elastase II and trypsin genes. Nucleic Acids Res 1986;14:8307-8330.

35. Swift GH, Hammer RE, MacDonald RJ, et al. Tissue-specific expression of the rat pancreatic elastase I gene in transgenic mice. Cell 1984;38:639-646.

36. Yasuda $T$, Ohmachi $Y$, Katsuki $M$, et al. Identification of novel pancreasspecific regulatory sequences in the promoter region of human pancreatic secretory trypsin inhibitor gene. J Biol Chem 1998;273:34413-34421.

37. Howard G, Keller PR, Johnson TM, et al. Binding of a pancreatic nuclear protein is correlated with amylase enhancer activity. Nucleic Acids Res 1989;17:8185-8195.

38. Chen SH, Estes LW, Lombardi B. Lecithin depletion in hepatic microsomal membranes of rats fed on a choline-deficient diet. Exp Mol Pathol 1972;17:176-186.

39. Leelavathi DE, Katyal SL, Lombardi B. Lecithin depletion in liver mitochondria of rats fed a choline-deficient diet. Effect on betahydroxybutyrate dehydrogenase. Life Sci 1974;14:1203-1210.

40. Lombardi B. Effects of choline deficiency on rat hepatocytes. Fed Proc 1971;30:139-142.

41. Howes N, Greenhalf W, Stocken DD, et al. Cationic trypsinogen mutations and pancreatitis. Clin Lab Med 2005;25:39-59.

42. O'Reilly DA, Kingsnorth AN. Hereditary pancreatitis and mutations of the cationic trypsinogen gene. Br J Surg 2000;87:708-717.

43. Guerassimov A, Hoshino $Y$, Takubo $Y$, et al. The development of emphysema in cigarette smoke-exposed mice is strain dependent. Am J Respir Crit Care Med 2004;170:974-980.

44. Shapiro SD. Animal models for chronic obstructive pulmonary disease: age of klotho and marlboro mice. Am J Respir Cell Mol Biol 2000; 22:4-7. 